NBER WORKING PAPER SERIES

\title{
THE IMPACT OF PRENATAL EXPOSURE TO COCAINE ON NEWBORN \\ COSTS AND LENGTH OF STAY
}

\author{
Theodore Joyce \\ Andrew D. Racine \\ Sandra McCalla \\ Hassan Wehbeh
}

Working Paper No. 4673

\section{NATIONAL BUREAU OF ECONOMIC RESEARCH \\ 1050 Massachusetts Avenue \\ Cambridge, MA 02138 \\ March 1994}

The research was supported by Grant Number 91-3973 from the David and Lucile Packard Foundation to the National Bureau of Economic Research. The research is part of NBER's research program in Health Economics. Any opinions expressed are those of the authors and should not be assumed to be those of the David and Lucile Packard Foundation or the NBER. We wish to thank Michael Grossman, Eugene Lewitt, and Bob Kaestner for ongoing advice and Andy Mosso, Geoffrey Joyce, and Patricia DeVries for technical assistance. 
NBER Working Paper \#4673

March 1994

\title{
THE IMPACT OF PRENATAL \\ EXPOSURE TO COCAINE ON NEWBORN \\ COSTS AND LENGTH OF STAY
}

\begin{abstract}
This paper determines newborn costs and lengths of stay attributable to prenatal exposure to cocaine and other illicit drugs, using as a data source all parturients who delivered at a large municipal hospital in New York City between November 18, 1991 and April 11, 1992. We performed a cross-sectional analysis in which multivariate, loglinear regressions were used to analyze differences in costs and length of stay between infants exposed and unexposed prenatally to cocaine and other illicit drugs adjusting for maternal race, age, prenatal care, tobacco, parity, type of delivery, birth weight, prematurity, and newbom infection. Urine specimens, with linked obstetric sheets and discharge abstracts provided information on exposure, prenatal behaviors, costs, length of stay and discharge disposition. Our principal findings show that infants exposed to cocaine and some other illicit drug stay approximately 7 days longer at a cost of $\$ 7,731$ more than infants unexposed. Approximately 60 percent of these costs are indirect, the result of adverse birth outcomes and newborn infection. Hospital screening as recorded on discharge abstracts substantially underestimates prevalence at delivery, but overestimates its impact on costs.

Theodore Joyce

Baruch College

Department of Economics and Finance

City University of New York

New York, NY 10027

and NBER

Sandra McCalla

Department of Obstetrics and Gynecology SUNY Health Science Center at Brooklyn 450 Clarkson Avenue, Room 362B

Brooklyn, NY 11203-2098

\author{
Andrew D. Racine \\ Albert Einstein College of Medicine \\ Department of Pediatrics \\ Pelham Pkwy. South \& Eastchester Rd. \\ Bronx, NY 10461-1602 \\ and NBER \\ Hassan Wehbeh \\ Department of Obstetrics and Gynecology \\ SUNY Health Science Center at Brooklyn \\ 450 Clarkson Avenue, Room 362B \\ Brooklyn, NY 11203-2098
}




\section{Introduction}

One of the most disturbing consequences of the surge in cocaine consumption during the latter half of the 1980's has been its impact on infant health. The clinical literature offers convincing evidence that newborns exposed prenatally to cocaine are more likely to be born preterm, suffer intrauterine growth retardation and have lower birth weights than infants born to similar mothers who are unexposed MacGregor et al. 1987; McCalla et al. 1991; Bateman et al. 1993). These outcomes are strongly associated with infant death and childhood morbidity (Institute of Medicine 1985).

Prenatal exposure to cocaine and other illicit drugs is extensive. In the most comprehensive prevalence study to date, urines from a population sample of over 29,000 women collected at delivery across California reveal that 7.79 percent of black women, .55 percent Hispanic, and .60 percent white were positive for cocaine (Vega et al. 1993). When exposure is expanded to include opiates, marijuana and amphetamines, prevalence at delivery rises to $14.22,2.75$, and 6.79 percent among blacks, Hispanics and whites respectively. Even these escimates are conservative since urine toxicological analysis can only detect exposure to certain drugs within 3 days of use (Ostrea et al. 1992). Application of these prevalence rates to national birth figures suggests that 287.800 black, white and Hispanic infants were exposed to illicit drugs in 1991 (National Center for Health Staristics 1993).

The economic consequences of prenatal illicit drug use are potentially enormous (Hay 1991). Even if costs are limited to the additional medical expenditures at delivery attributable directly to exposure, they may be sizeable given the technological sophistication of interventions available to treat premature and low birth weight infants. Moreover, unlike users of tobacco and alcohol, taxes cannot be imposed easily on users of illicit drugs so that much of the cost associated with the use of these substances will be borne by the population of nonusers. The existence of these external medical costs attributable to illicit drug use raises difficult questions as to how the cost burden will be distributed and what policies might best minimize it.

Despite the magnitude of the problem and the policy questions it engenders, there bas been relatively Linle research that specifically addresses the economic costs associated with prenatal drug use. One problem has been the lack of reliable data on both exposure and costs with sufficient cases to allow for multivariate analyses. 
Clinical reports have doçumented increased length of stay and increased use of intensive care nurseries for exposed as compared to unexposed newborns (Hurt et al. 1989; Noble et al. 1989), and for infants exposed to cocaine relative to opiates (Kaye et al. 1989). In the former two studies, however, small sample sizes precluded any multivariate analysis and in the latter, exposure was based on self-reports. Research suggests that analyses of birth outcomes based on maternal self-reports yield effects of exposure that are biased downwards (Zukemman et al. 1989).

The General Accounting Office (GAO) based on a survey of 10 urban hospitals reported median charges for newborn care between $\$ 1,100$ and $\$ 4,100$ above those of unexposed infants. As in the study by Kaye et al. (1989) that used self-reports, this investigation derived data on exposure from information recorded on charts. A second difficulty with the data from this study was that monetary differences were based on charges and not costs.

In a recent study which overcame many previous deficiencies, the authors examined newborn costs and length of stay for all singleton births exposed to cocaine at Harlem Hospital between September 1985 and August 1986 (Phibbs, Bateman, Schwartz 1991). During this period, toxicologic screens of all newborn urines and maternal self-reported histories were used to ascertain exposure during pregnancy. Adjusting for characteristics of the mother, authors reported that newbom length of stay and costs attributable to cocaine or its derivatives (j.e. "crack") ranged from 4 to 10 additional days at a cost of between $\$ 2,600$ and $\$ 8,450$ in 1990 dollars.

Although this study represents a major improvement over previous work, its estimates of both length of stay as well as costs are problematic for several reasons. First, between 1983 to 1987 New York State hospitals were reimbursed on a prospective per diem basis. If infants exposed to illicit drugs provided net gains to per diem revenues, especially towards the end of the stay, then length of stay and thus costs reported under such a system could be inflated. Second, cost information was based on the Medicare system of DRG's, a reimbursement mechanism designed primarily for the care of the elderly. As the authors acknowledge, the 7 case groups designed to capture newborn costs have large variances within groups. Third, regression estimates did not take into account the non-negativity and skewness of the data on length of stay and costs. Consequently. 
statistical inferences may be misleading.

In this paper, we estimate newbom costs and length of stay associated with prenatal exposure to cocaine. The objectives are threefold: first, to improve on estimates in the clinical literature with greater attention to unbiased exposure measures, more accurate cost data, and more appropriate statistical analysis; second, to explore the mechanisms through which antenatal exposure to iliicit drugs may.exert its effects on newborn length of stay and costs and; third, to compare costs and length of stay for patients in whom exposure is known to medical providers compared to those in whom exposure remains occult.

\section{Empirical Implementation}

To structure the empirical work, we postulate that physicians maximize the sum of $h_{2}$, the difference between child health at birch $\left(\mathrm{H}_{0}\right)$ and child health at discharge $\left(\mathrm{H}_{1}\right)$. Infant health is improved by increasing length of stay $(L)$, which represents an aggregation of inputs available to physicians. Length of stay is constrained by the number of newbom beds at the hospital, which is fixed. If a newborn's initial health is good, then the difference between $H_{1}$ and $H_{0}$ will be small, and the physician will conserve scare resources $(\mathrm{L})$ for less healthy newborns, those with a smaller $\mathrm{H}_{0}$. An important feature of the franework is that physicians, not parents, are the decision makers. Physician choices regarding length of stay take prenatal behaviors and birth outcomes as given. Thus, we view newborn costs and length of stay functions as reduced forms."

Dạa

We included all women who delivered at a municipal hospital in New York City between November 18, 1991 and April 11, $1992(\mathrm{~N}=1,323)$. Specimens obtained for routine urinalysis from parturients were collected within 24 hours of admission to the labor and delivery unit. All urine samples were refrigerated and transported within 48 hours to the institution's toxicology laboratory. Information routinely collected from parturients was recorded on data sheets which were given the same code number as the urine specimens. Data included demographic information, history of exposure (cocaine, marijuans, heroin, methadone and tobacco), and prenatal care. Data on birth outcomes, length of stay, expected reimbursement, and discharge disposition were. from discharge abstracts.

To preserve confidentiality of study women we gave each data sheet and urine specimen the same case 
number. Neither had any personal identifiers. We kept a separate file that contained only case numbers and the mother's medical record numbers. This file was used by personnel in the Medical Records department to link mother and infant to discharge abstracts. The file was returned to us with only case numbers and relevant discharge information. We linked discharge information, data sheets, and urine toxicology results by case number.

We were unable to obtain medical record numbers for 34 infants. Two of the 34 infants were unlikely to have survived given birh weights of 400 and 520 grams. Excluding these 2 newborns, the mean characteristics of the other 32 mothers and infants based on the survey data were not statistically significant along a host of characteristics (available upon request). An additional 8 other infants died in the hospital and 2 others were transferred. Elimination of these 44 records, reduced the sample to 1,279 mothers whose infants survived the initial stay.

We analyzed three outcomes: 1) the number of days the infant stayed in the hospital following delivery that was certified to be medically necessary; 2) cost per discharge; 3) the service intensity weight associated with each case. Cost per case is based on the New York Prospective Hospital Reimbursement Methodology (NYPHRM IV). Under NYPHRM IV, each discharge is assigned to a diagnostic related group (DRG); there are 37 DRG's for newborns. The service intensity weighi for each DRG is multiplied by the case payment rate, a weighted average of the hospital-specific costs ( 45 percent) and peer group costs ( 55 percent). The case payment rate for municipal hospitals includes the cost of capital, physician services, medical education and indigent care. As an alternative expression of relative resource use, we present regressions with service intensity weights (SIW) as the dependent variable. Service intensity weights reflect relative costs among the 600 DRG's in the New York State system. Thus, a case assigned an SIW of .5 costs half as much, on average, as a case with a SIW of 1.0. The SIW's are based on a one-third sampling of all discharges in the State, the most recent being 1989 (New York State Department of Health 1991). Loosely, we view cost per discharge as hospital-specific because it incorporates capital costs, physician services and indigent care at this particular facility; SIWs, by contrast, reflect the average experience of all hospitals and include only costs comparable across institutions. 
Certified length of stay is the number of aays determined to be medically necessary. We excluded days in alternate levels of care because they are specific to the facility and the local child welfare policies. In our sample 51 infants had stays that exceeded the number of days that were medically necessary. The average number of days in excess of the medically mecessary stay was 7.6.

Of the 1279 women/infant pairs in the final sample, 143 or 11.2 percent were exposed to one or more drugs. We categorized exposure as follows: 1) cocaine exclusively $(\mathrm{N}=34) ; 2)$ drugs other than cocaine marijuana, heroin, or methadone $(\mathrm{N}=58)$; and 3) cocaine and some other drug $(\mathrm{N}=51)$. To facilitate discussion we use the following acronyms: EC for exclusively cocaine, DOC for drugs other than cocaine, and CPOD for cocaine phus other drugs. The three drug categories were further classified by how exposure was determined. If exposure was ascerained by anonymous survey, and was not recorded on discharge abstracts, we refer to these cases as exposures unknown to physicians $(\mathrm{N}=101 ; 71 \%$, of total exposures). Because exposures reported on discharge abstracts were based on information in a mother's or infant's chart, we consider these cases as exposures known to physicians $(N=42$ or $29 \%$ of total exposures).

Other covariates include mother's age, race, tobacco use during pregnancy (yes or no), prenatal care, parity and cesarean delivery. Mother's race was categorized as follows: African American, non-American black, Hispanic, white and Asian. Eighty-five percent of the women included in the study were black. We dichotomized race between African American (30 percent) and all others since preliminary analysis revealed this to be the only statistically important distinction. Prenatal care was also dichotomized between women who had at least 4 visits and women who had less than 4 visits or who were unregistered for prenatal care at the hospital. As with maternal race, more refined categorizations offered no additional insights. Finally, we used three measures of infant health at delivery: birth weight measured in grams, a dichotomous indicator of prematurity, and a dichotomous indicator of newborn infection. The latter two indicators were based on International Classification of Disease, Ninth Edition (ICD-9) codes on the infant or mother's discharge abstract. A complete listing of which ICD-9 codes were used for each measure is available upon request.

\section{Econometric specification}

Both length of stay and newborn costs are strictly positive. Plots of the distributions (not shown) 
revealed obvious skewness. Given these characteristics, we use the natural logarithm of each as the dependent variable and White's estimator as a correction for heteroscedasticity. ${ }^{3}$

We estimate two specifications for each outcome. The first includes our three measures of infant health at delivery. The coefficients on illicit drug use in this specification capture what we term the direct effects of exposure on newborn costs and length of stay. The second,specification excludes measures of newborn health. The restriction allows us to estimate the total effect of cocaine exposure on newborn costs and length of stay, since it captures the indirect effects of exposure on birth outcomes and maternal transmission of infection.

Results

Table 1 presents summary statistics stratified by drog use. We call attention to the obvious gradient moving from left to right across this table. CPOD users are more likely than EC users, who in turn are more likely than DOC users, to be African American, to have less than 4 prenatal care visits, to have smoked during pregnancy, to have lower mean birth weights, higher rates of low birth weight, very low birth weight, and newborn infection. Similar gradients hold for newborn length of stay, costs and service intellsity weiglus. Finally, the second to last row in Table 1 shows that discharge abstracts are nore likely to record indications of CPOD use than EC or DOC use.

Results from anonymous screen

The regression results in Table 2 are consistent with the initial findings reported in Table 1 . Newborns exposed to CPOD have longer stays, at substantially higher cost than infants unexposed to any drugs. Based on the specifications which exclude measures of newborn health, CPOD exposure is associated with a 131 percent increase in length of stay (column 1), a 282 percent increase in hospilal specific costs (column 3) and a 300 percent increase in relative costs (column 5). By contrast, EC use is associated with a 27 percent increase in length of stay (column 1) and a 45 percent increase in costs (column 3). Both effects are marginally significant. The use of DOC has little impact on costs and length of stay.

Another noteworthy finding is that only CPOD use is robust to the inclusion of newborn health at delivery [columns (2), (4), (9)]. This signifies strong direct cost effects of CPOD exposure since its coefficients fall by at most 42 percent when birth weight, prematurity and infant infection are added to the 
specifications. By comparison, the coefficients on prenatal care and multiple births, covariates with strong indirect effects, fall to zero with the inclusion of newborn health [columns (2), (4), (0)]. Even when we add additional indicators of newborn bealth, such as fetal distress, respiratory distress, and drug withdrawal, coefficients on CPOD use remain essentially unchanged (results not shown). From a statistical perspective the robustness of the coefficients on CPOD is impressive because measures of infant health increases the adjusted R-squared dramatically, from between .10 and .22 to upwards of .67 .

To transform the loglinear regression coefficients into length of stay and cost effects expressed in days and dollars, we summarize in Tables 3 and 4 the total and direct effects of illicit drug exposure by type of drug. In each table we show predicted length of stay and newborn costs for infants exposed and unexposed to each of the three dug categories. Estimates are evaluated for infants born to sample women whose characteristics put them at high risk for an adverse birh oulcome.' Differences in outcomes between exposed and unexposed infants shown in column 3 reveal marginal effects of illicit drug use.

Tables 3 and 4 underscore the strong association between CPOD use and newborn costs and length of stay. Total effects of exposure shown in Table 3 indicate that infants exposed to CPOD stay in the bospital, on average, 6.6 days more at a cost of $\$ 7,731$. The marginal costs of EC exposure are notably less $(\$ 1,223)$, and the comparatively small impact of $D O C$ use is statistically unmeaningful. Direct effects of exposure are substantially less (Table 4). Holding aewborn health at delivery constant, infants exposed to CPOD stay 2.4 days longer at an incremental costs of $\$ 3,114$. Thus approximately 60 percent of total newborn costs associated the CPOD exposure are the consequence of adverse birth outcomes and aewborn infection.

\section{Comparison with discharge abstracts}

To determine whether the association between newborn costs and length of stay is greater when exposure is known to clinicians than when it is unknown, we re-estimated the regressions in Table 2 with separate indicators for known and unknown drug use. Recall that if exposure were recorded on discharge abstracts we considered it known to clinicians. If exposure was not indicated on the discharge abstract, but was captured by anonymous screen, we regarded it as unknown to clinicians. The results appear in Table 5. To simplify the exposition, we only show coefficients on drug use. 
For infants exposed to EC at the time of delivery, differences in costs and length of stay between known and unknown exposure are dramatic. Infants whose exposure to EC is known to clinicians have stays almost 100 percent greater and newborn costs at least 180 percent greater than unexposed infants. By contrast, we find no association between unknown exposure to EC and newbor costs and length of stay. A chi-squared test rejects the null of no difference between known and unknown EC exposure in 4 of 6 specifications. We obtained the same result for infants exposed to-DOC. Known exposure is associated with large and highly significant increases in costs and length of stay; unknown exposure is not. By contrast, there are no meaningful differences in the costs between known and unknown exposures to CPOD.

The results in Table 5 suggest that selective screening of women or infants for exposure to cocaine and other drugs as recorded on discharge abstract would bias upwards, except in the case of CPOD use, the estimated costs associated with exposure. To make this point more formally, we reran the regressions in Table 2 substituting known exposure for actual exposure. Thus, infants classified as unexposed in these regressions included a subset of newboms who were positive for an illicit substance at delivery as determined by the anonymous screen, but not recorded on discbarge abstracts (see Table A-1 in the Appendix).

We used the coefficients from these regressions to predict total costs and length of stay for newborns. We used the same maternal characteristics as in Table 3 and 4 to evaluated the estimates." Results are presented in Tables 6 and 7. As noted on discharge abstracts, infants exposed to EC stay, on average, 4.6 days longer at marginal cost of $\$ 4,830$. If cost and stays are taken from specifications which include measures of newborn health, marginal costs fall to $\$ 1,122$ (Table 7 ). These results are in sharp contrast to comparative estimates reported in Tables 3 and 4 . The marginal costs associated with known DOC exposure differ even more dramatically than those reported in Tables 3 and 4 . Infants exposed to DOC as recorded on discharge abstracts have marginal costs of $\$ 6,165$ with additional stays of 3 days (Table 6). When we control for newborn health, marginal costs fall, but are still substantial (Tabie 7). Differences between predicted costs and length of stay for CPOD users are higher than those reported in Tables 3 an 4 , but the differences are not statistically significant. 


\section{National costs of exposure}

We conclude this section with projections of the marginal newborn costs of exposure at the national. level for blacks, whites and Hispanics. This exercise is speculative because our cost estimates are from a single institution. Thus, we use estimates of the total and direct costs of exposure in order to bracket our

calculations. We believe the direct costs are conservative because they minimize the indirect costs of exposure associated with adverse birth outcomes. Births are from 1991 (National Ceater for Health Statistics 1993).

Prevalence estimates for cocaine and opiates are from California (Vega et al. 1993). We assume that 60 percent of all cocaine users are CPOD based on the distribution in our sample (51/85).

We estimate that EC and CPOD exposure have added 360 million dollars to newborn costs in 1992 dollars. We assume the marginal cost of DOC is zero based on the results in Table 3. If we use only the direct costs of exposure (Table 4), marginal costs fall to 132 million dollars. We recomputed the estimates using costs per exposure as recorded on discharge abstracts. Based on total costs (Table ), we find exposure adds 929 million dollars to newborn costs nationally. If we limit projections to only direct costs, we find that exposure is associated with an increase of 387 million dollars nationally.

\section{Discussion}

We have found that newborns prenatally exposed to cocaine plus other drugs (CPOD) are three times more costly to care for after delivery than infants unexposed at a large municipal hospital in New York City. Exposure to exclusively cocaine (EC) is associated with a 44 percent increase in costs whereas exposure to drugs other than cocaine (DOC) has no meaningful association with newborn costs.

The findings are in general agreement with Phibbs, Bateman and Schwartz (1991) who also found that women exposed to cocaine plus other drugs had the greatest increase in costs and length of stay. The magnitude of increases reported by Phibbs, Bateman and Schwartz (1991) are substantially greater than ours. They report, for instance, incremental stays of 10 days for infants exposed to cocaine and other drugs, an effect 50 percent greater than the 6.6 days we report. If we adjust their costs for inflation and add 20 percent for physician services, the marginal costs of exposure to cocaine pius other drugs reported in their study rise to $\$ 11,864$, a sum also 50 percent greater than ours. The difference may be attributable, in part, to the New 
York State prospective per case reimbursement system which provides powerful incentives to minimize length of stay. As noted above, this system did not become effective until 1988, two years after the study by Phibbs, Bateman and Schwartz (1991) was conducted.

In addition to improved cost estimates we bave also elucidated some of the mechanisms through which antenatal exposures to illicit drugs exert their effects. We found we could account for all of the length of stay and cost effects of EC and DOC exposure by including gestational age, birth weight and congenital infection in the analysis as independent predictors. Only CPOD showed substantial direct effects independent of these birth outcome variables though the length of stay and cost effects of CPOD decreased by over $40 \%$ when the birth outcome factors were included.

There are important policy implications to these findings. Programs designed to amelionate prematurity, low birth weight and congenital infection may be predicted to demonstrate substantial cost savings among individuals with prenatal illicit drug exposures whether or not treament is directed specifically at eliminating the underlying exposure. Evidence of this effect has been demonstrated with respect to llee association of prenatal care on birth weight among cocaine exposed individuals (Racine, Joyce, and Anderson 1993).

Another noteworthy fiuding is that where exposure to EC or DOC was recorded on discharge abstracts, the affected neonates were found to stay longer and were more costly to care for than where exposure was ascertained only by anonymous screen. These were the same exposures for which we were unable to demonstrate significant direct effects on costs and length of stay after including premanurity, birth weight and congenital infection in the analysis. By contrast, we found no significant differences in outcomes between CPOD users identified on discharge abstracts and those found on the anonymous screen and at the same time were able to demonstrate strong direct effects for these exposures.

If we consider identification on discharge summaries as similar to self-reporting of illicit substance use, these findings are consistent with a study which used meconium analysis to screen for exposure. Ostrea et al. (1992) demonstrated that infants whose meconium was positive for illicit substances and whose mothers admitted use had more adverse clinical outcomes than infants whose meconium was positive but whose mothers denied 
use.

Two competing explanations may be invoked 10 account for these findings. On the one hand it could be argued that physicians, once aware of a patient's exposure status, behave more conservatively. They may order more tests, consider more intensive treatments for medical conditions, observe newborns for longer periods and, in general, strive to avoid undertreatment of such individuals whether or not their condition clinically warrants this more resource-intensive approach. On the other hand, it may be that certain readily observed conditions associated with more severely affected individuals provoke medical personnel to search more intensively for evidence of exposure. A typical example would be a woman who was unregistered for prenatal care or who screened positive for a sexually transmitted disease.

Our data, we believe, support the latter contention. We found that infants whose exposure to EC was recorded on discharge abstracts (what we have referred to as known exposure) had smaller mean birth weights. greater rates of low birth weight and their mothers received less prenatal care than infants whose exposure was unknown. Among DOC users, differences in smoking were significant while differences in mean birdl weights and rates of low birth weight were sizable, but statistically insignificant.'

The fact that we could not demonstrate equivalent differences in costs and length of stay for CPOD users identified by medical providers compared to those identified on the anonymous screen is also consistent with this explanation given the large direct effects we found. While it appears that a greater proportion of CPOD users were more severely affected and thus more readily identified than EC or DOC users (see Table 1), a significant portion of the effect of CPOD exposure was found to be independent of the conditions that might ordinarily motivate a provider to screen for exposure. Under these circumstances providers who depend upon factors such as birth weight; receipt of prenatal care, gestational age, etc. to determine who they should screen are unable to predict who is likely to be exposed. The result is that the unscreened CPOD users have clinical outcomes similar to screened CPOD users.

The epidemic of antenatai exposure to illicit substances is a serious threat to the health of pregnant women and their newborn offspring. The paradoxical results of our investigation, however, indicate that while the extent of the epidemic is, as others have found, far greater that what has been estimated on the basis of 
clinical reports from discharge summaries alone, the clinical and cost impact of exposure is significantly smaller than what estimates from these sources would indicate.

Finally, it is somewhat reassuring that for exposure to cocaine alone or drugs other than cocaine, at least in the setting of an urban hospital with ongoing experience of the epidemic, those women most severely affected appear to be identified with little difficulty. The same sanguine appraisal cannot be substantiated for women who use cocaine together with other drugs. The offspring of these women not only appear to have worse clinical outcomes with larger consequent deonatal costs, but the ability of the medical system to identify them prospectively is limited. 
1. External costs are those imposed on nonusers. See Hay (1991) and Manning et al. (1989).

2. The separation of physicians and parents is more problematic among private service patients who have an ongoing relationship with a particular obstetrician. In this case, prenatal behaviors are endogenous. In anticipation of an adverse outcome, the physician as perfect agent recommends interventions prior to birth (e.g., a smoking cessation program) in order to conserve resources postnatally. At municipal hospitals in New York City, the majority of births are public service deliveries and in our sample, 50 percent of all exposed women had 3 or less prenatal visits, which suggests a minimal level of patient/physician interaction.

3. We use a Lagrange Multiplier test for heteroscedasticity (Breusch and Pagan 1980). In all 6 specifications we rejected the null hypothesis of homoscedasticity decisively.

4. The percent changes are equal to $100^{*}\left(e^{b_{i}}-1\right)$ where $\beta_{i}$ is the coefficient on illicit dng use.

5. The specific characteristics are in the footnotes to Tables 3 and 4. Marginal effects were relatively insensitive to variations in the characteristics of the mother.

6. See footnotes to Table $\mathbf{3}$ and $\mathbf{4}$ for a list of characteristics.

7. These comparisons are available upon request. 


\section{References}

Bateman, D., S. Ng, C. Hansen, and M. Heagarty. "The Effects of Intrauterine Cocaine Exposure in Newborns." American Joumal of Public Health 83 (1993): 190-3.

Breusch, P. and A. Pagan "A Simple Test for Heteroscedasticity and Radom Coefficient Variation." Econometrica 47 (1980): 1287-94.

Calhoun, B. C. and P. T. Watson. "The Cost of Maternal Cocaine Abuse: I Perinatal Cost." Obstetrics \& Gypecology 78 (1991): 731-34.

General Accounting Office. Drug Exposed Infants: A Generation at Risk. Washington, DC: US General Accounting Office; 1990. Publication GAO/HRD-90-138.

Hay, J. "The Harm They Do to Others." In Searching for Alternative: Dng Control Policies in the United States. Edited by M. B. Krauss and E. P. Lazear. Stanford, CA: Hoover Institution Press, 1991, pp. $200-25$

Hur, H., R. Porat, D. Gedon, et al. "Nursery Length of Stay is Increased in Infants of Cocaine-abusing Mothers." Pediatric Research (1989): 254A.

Institute of Medicine. Preventing Low Birth Weight. Washington, D.C.: National Academy Press, 1985.

Kaye, K., L. Elkind, D. Goldberg, and A. Tytun. "Birth Outcomes for Infants of Drug Abusing Mothers." New York State Journal of Medicine 89 (1989): 256-61.

MacGregor, S. N., L. G. Keith, I. J. Chasnof, et al. “Cocaine Use During Pregnancy: Adverse Perinatal Outcome." American Journal of Obstetrics and Gynecology 157 (1987): 686-90.

Manning, W., E. Keeler, J. Newhouse, et al. 'The Taxes of Sin: Do Smokers and Drinkers Pay Their Way?" Lournal of the American Medical Association 262 (1989): 1604-9. 
McCalla, S., H. L. Minkoff, J. Feldman J., et al. "The Biologic and Social Consequences of Perinatal Cocaine Use in an Inner-city Population: Resules of an Anonymous Cross-sectional Study." American Journal of Obstetrics and Gynecology 164 (1991); 625-30.

National Center for Health Statistics. "Advance report of final natality statistics, 1991." Monthly.Vital Statistics Report. Vol. 42, No. 3, Suppl: Hyattsville, MD. Public Health Service 1993.

New York State Department of Health. Hospital Reimbursement in New York State (NYPHRM IV). Division of Health Care Financing, Office of Health Systems Management, New York State Department of Health. 1991.

Noble, L. M., K. Machee, R. T. Checola, et al. "Cost of Maternal Drug Use on Neonatal Care in the South Bronx." Pediatric Research (1989): 225A.

Ostrea, E., M. Brady, S. Ganse, et al, "Drug Screening of Newborns by Meconium Analysis: A Large-scale, Prospective, Epidemiologic Study." Pediatrics 89 (1992): 107-13.1

Phibbs, C. "The Economic Implications of Substance Abuse." Furure of Children 1 (1991) 113+120.

Phibbs, C., D. A. Bareman, and R. Schwartz. "The Neonatal Costs of Maternal Cocaine Use." Journal of the American Medical Association 266 (1991): 1521-6.

Racine, A. T. Joyce, and R. Anderson. "The Association Between Prenatal Care and Birth Weight Among Women Exposed to Cocaine in New York City." Joumal of the American'Medical Association 270 (1993): $1581-86$.

Vega, W., B. Kolody, J. Hwang, and A. Noble. "Prevalence and Magnitude of Perinatal Substance Exposures in California." New England Joumal of Medicine 329 (1993): 850-4.

Zukemnan, B., D. Frank, R. Hirgson, et al. Effects of Maternal Marijuana and Cocaine Use on Fetal Growth." New England Joumal of Medicine 320 (1989): $762-8$. 
Table 1

Summary Means and Frequencies by Type of Exposure

(percentages unless stated)

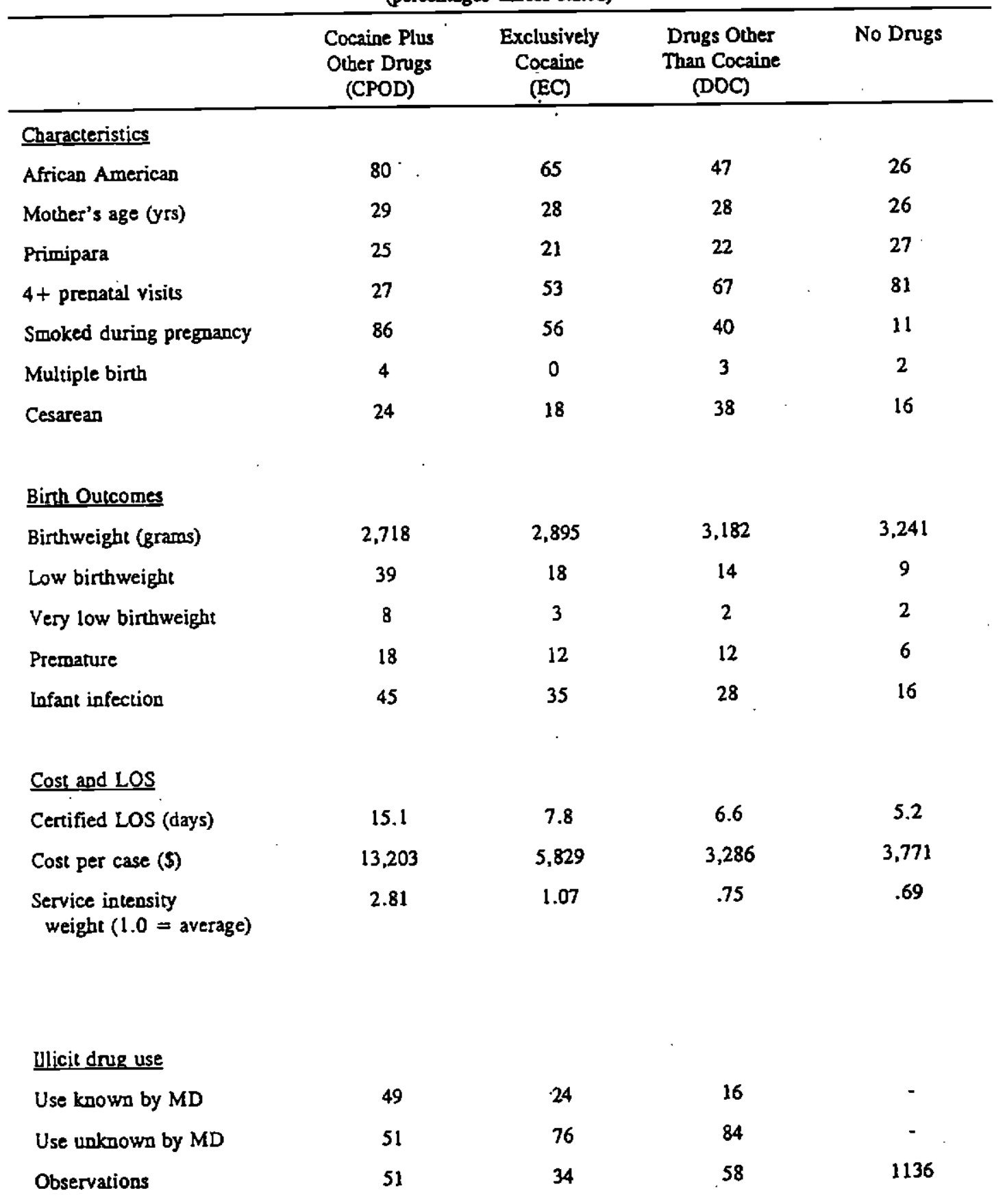


Table 2

Log Linear Regressions of

Newborn Length of Stay, Cosis and

Service Inlensity Weights"

\begin{tabular}{|c|c|c|c|c|c|c|}
\hline \multirow[t]{2}{*}{$\cdot$} & \multicolumn{2}{|c|}{ Length of Stay } & \multicolumn{2}{|c|}{ Newbora Costs } & \multicolumn{2}{|c|}{ Serviee Lotensity Weight } \\
\hline & $\begin{array}{c}\text { Total } \\
\text { (1) }\end{array}$ & $\begin{array}{l}\text { Direcl } \\
\text { (2) }\end{array}$ & $\begin{array}{l}\text { Total } \\
\text { (3) }\end{array}$ & $\begin{array}{l}\text { Direct } \\
\text { (4) }\end{array}$ & $\begin{array}{l}\text { Tolal } \\
\text { (S) }\end{array}$ & $\begin{array}{l}\text { Direct } \\
(6)\end{array}$ \\
\hline Constant & $\begin{array}{l}1.71 \\
(.27)\end{array}$ & $\begin{array}{l}8.23 \\
(.90)\end{array}$ & $\begin{array}{l}7.97 \\
(.37)\end{array}$ & $\begin{array}{l}18.29 \\
(1.31)\end{array}$ & $\begin{array}{l}-.70 \\
(.32)\end{array}$ & $\begin{array}{c}9.94 \\
(1.03)\end{array}$ \\
\hline Multiple Birth & $\begin{array}{l}.64^{-} \\
(.19)\end{array}$ & $\begin{array}{l}.09 \\
(.10)\end{array}$ & $\begin{array}{l}.62^{-} \\
(.23)\end{array}$ & $\begin{array}{l}-.11 \\
(.14)\end{array}$ & $\begin{array}{l}.46^{\circ} \\
(.25)\end{array}$ & $\begin{array}{l}-.29^{-} \\
(.15)\end{array}$ \\
\hline Cesarean & $\begin{array}{l}.63^{\cdots \cdots} \\
(.05)\end{array}$ & $\begin{array}{l}.52- \\
(.03)\end{array}$ & $\begin{array}{l}.20^{-0 *} \\
(.08)\end{array}$ & $\begin{array}{l}.09 \\
(.06)\end{array}$ & $\begin{array}{l}.25 \\
(.08)\end{array}$ & $\begin{array}{l}.14^{-5} \\
(.05)\end{array}$ \\
\hline Log age & $\begin{array}{l}-.11 \\
(.08)\end{array}$ & $\begin{array}{c}.06 \\
(.06)\end{array}$ & $\begin{array}{l}-.16 \\
(.10)\end{array}$ & $\begin{array}{c}.07 \\
(.08)\end{array}$ & $\begin{array}{l}-.10 \\
(.09)\end{array}$ & $\begin{array}{l}.14^{-3} \\
(.06)\end{array}$ \\
\hline Primipara & $\begin{array}{l}-.09 " \\
(.04)\end{array}$ & $\begin{array}{l}. .05^{\circ} \\
(.03)\end{array}$ & $\begin{array}{l}-.07 \\
(.06)\end{array}$ & $\begin{array}{l}. .02 \\
(.05)\end{array}$ & $\begin{array}{l}-.04 \\
(.05)\end{array}$ & $\begin{array}{l}.01 \\
(.03)\end{array}$ \\
\hline $\begin{array}{l}\text { Smoked during } \\
\text { preguancy }\end{array}$ & $\begin{array}{l}.02 \\
(.06)\end{array}$ & $\begin{array}{c}.01 \\
(.04)\end{array}$ & $\begin{array}{l}. .03 \\
(.08)\end{array}$ & $\begin{array}{l}-.04 \\
(.06)\end{array}$ & $\begin{array}{l}-.01 \\
(.08)\end{array}$ & $\begin{array}{l}.03 \\
(.04)\end{array}$ \\
\hline 4+ Predaral Visiss & $\begin{array}{l}-.28^{\cdots} \\
(.06)\end{array}$ & $\begin{array}{l}-.05 \\
(.03)\end{array}$ & $\begin{array}{l}. .09 \\
(.09)\end{array}$ & $\begin{array}{l}.19^{-*} \\
(.06)\end{array}$ & $\begin{array}{l}-.33^{\cdots 0} \\
(.07)\end{array}$ & $\begin{array}{l}. .02 \\
(.04)\end{array}$ \\
\hline African American & $\begin{array}{l}.04 \\
(.05)\end{array}$ & $\begin{array}{c}.02 \\
(.03)\end{array}$ & $\begin{array}{l}.10 \\
(.07)\end{array}$ & $\begin{array}{l}.08 \\
(.05)\end{array}$ & $\begin{array}{l}.10 \\
(.06)\end{array}$ & $\begin{array}{l}.07 \\
(.04)\end{array}$ \\
\hline $\begin{array}{l}\text { Exelusively cocaine } \\
\text { (EC) }\end{array}$ & $\begin{array}{l}.24^{\circ} \\
(.14)\end{array}$ & $\begin{array}{l}-.002 \\
(.10)\end{array}$ & $\begin{array}{l}.37^{-} \\
(.18)\end{array}$ & $\begin{array}{l}.06 \\
(.13)\end{array}$ & $\begin{array}{l}.34^{\circ} \\
(.18)\end{array}$ & $\begin{array}{l}.03 \\
(.12)\end{array}$ \\
\hline $\begin{array}{l}\text { Drugs other than } \\
\text { cocaine (DOC) }\end{array}$ & $\begin{array}{l}.15^{\circ} \\
(.09)\end{array}$ & $\begin{array}{l}.06 \\
(.07)\end{array}$ & $\begin{array}{l}.14 \\
(.14)\end{array}$ & $\begin{array}{l}.11 \\
(.12)\end{array}$ & $\begin{array}{l}.22 \\
(.12)\end{array}$ & $\begin{array}{c}.11 \\
(.09)\end{array}$ \\
\hline $\begin{array}{l}\text { Cocaine plus other } \\
\text { drugs (CPOD) }\end{array}$ & $\begin{array}{l}.84 * \\
(.13)\end{array}$ & $\begin{array}{l}.49^{-} \\
(.08)\end{array}$ & $\begin{array}{l}1.34^{-\infty} \\
(.18)\end{array}$ & $\begin{array}{l}.95 \\
(.12)\end{array}$ & $\begin{array}{l}1.40^{-} \\
(.17)\end{array}$ & $\begin{array}{l}.95 \\
(.10)\end{array}$ \\
\hline Log birth weight & & $\begin{array}{l}. .92^{-} \\
(.11)\end{array}$ & & $\begin{array}{l}-1.42^{-} \\
(.16)\end{array}$ & & $\begin{array}{c}-1.46^{-} \\
(.13)\end{array}$ \\
\hline Premature & & $\begin{array}{l}.58^{-5} \\
(.10)\end{array}$ & & $\begin{array}{l}.73^{-} \\
(.15)\end{array}$ & & $\begin{array}{l}.67^{-\infty} \\
(.13)\end{array}$ \\
\hline Infant lnfection & & $\begin{array}{l}.77^{+\infty} \\
(.05)\end{array}$ & & $\begin{array}{l}.79^{-0} \\
(.07)\end{array}$ & & $\begin{array}{c}.89^{-} \\
(.05)\end{array}$ \\
\hline$N$ & 1279 & 1279 & 1271 & 1271 & 1277 & 1277 \\
\hline Adj $\mathbf{R}^{2}$ & .22 & .64 & .10 & .47 & .17 & .67 \\
\hline$F$ & 37.6 & 170.7 & 15.1 & 19.1 & 27.6 & 202.4 \\
\hline
\end{tabular}

- Standard errors (in pareatheses) bave been corrected for beteroskedasticity with White's (1980) estimator. Dichotomous variables are 1 if true and zero otherwise. The two continuous variables, mother's age and birth weight, are expressed as aatural logarithms.

$-p<.10$

$p<.05$

$-p<.01$ 
Table 3

Predicted length of stay and newborn costs for infants exposed and unexposed to exclusively cocaine (EC), drugs other than cocaine (DOC), and cocaine plus other drugs (CPOD) from specifications which exclude measures of newbom health. ${ }^{a, b}$

Exposed Unexposed Difference

\section{EXCLUSIVELY}

COCAINE

Length of stay

6.4

5.0

1.4

Newborn costs

$\$ 3,957$

$\$ 2,734$

$\$ 1,223$

DRUGS OTHER THAN

COCAINE

Length of stay

5.9

5.0

0.9

Newborn costs

$\$ 3,132$

$\$ 2,734$

$\$ 398$

COCAINE PLUS

OTHER DRUGS

Length of stay

11.6

5.0

6.6

Newborn costs

$\$ 10,465$

$\$ 2,734$

$\$ 7.731$

"Predicted values were calculated as $\exp (\ln y) * \exp \left(\sigma_{e}^{2} / 2\right)$ where $\ln y$ is predicted cost or length of stay and $\sigma_{1}^{2}$ is the associated standard error of the estimate.

${ }^{b}$ Characteristics of women are as follows: singleton birth, vaginal delivery, 28 years old, smoked during pregnancy. less than four prenatal care visits, and African American. 
Table 4

Predicted length of stay and newborn costs for infants exposed and unexposed to exclusively cocaine (EC), drugs other than cocaine (DOC), and cocaine plus other drugs (CPOD) from specifications which include measures of aewborn bealth. at

Exposed Unexposed Difference

\section{EXCLUSTVELY \\ COCAINE}

Length of stay

$3.7^{-}$

3.7

0

Newborn cosis

$\$ 2,094$

$\$ 1,978$

$\$ 116$

DRUGS OTHER THAN

COCAINE

Length of stay

Newborn costs

COCAINE PLUS

OTHER DRUGS

Length of stay

Newborn costs
3.9

$\$ 2,000$

6.1

$\$ 5,092$
3.7

0.2

$\$ 1,978$

$\$ 22$

3.7

2.4

$\$ 3,114$

*Predicted values were calculated as exp $(\ln y) * \exp \left(\sigma_{1}^{2} / 2\right)$ where ln $y$ is predicted cost or length of stay and $\sigma_{1}^{2}$ is the associated standard error of the estimate.

'Characteristics of women are as follows: singleton birth, yaginal delivery, 28 years old, smoked during pregnancy, less than four prenatal care visits, and African American (infant's weight 2718 grams, not premature, and no infection). 
Table 5

Coefficients on known and unknown dng use in loglinear regressions of length of stay, newborn costs and service intensity weights

\begin{tabular}{|c|c|c|c|c|c|c|}
\hline & \multicolumn{2}{|c|}{ Length of stay } & \multicolumn{2}{|c|}{ Newborn costs } & \multicolumn{2}{|c|}{ Service intensity weights } \\
\hline & Total & Direct & Total & Direct & Total & Direct \\
\hline \multicolumn{7}{|l|}{ Exclusively Cocaine } \\
\hline Known & $\begin{array}{l}.68^{\cdots} \\
(.24)\end{array}$ & $\begin{array}{c}.29 \\
(.25)\end{array}$ & $\begin{array}{l}1.03^{-\infty} \\
(.42)\end{array}$ & $\begin{array}{l}.50^{--} \\
(.21)\end{array}$ & $\begin{array}{l}1.15^{\circ} \\
(.43)\end{array}$ & $\begin{array}{l}.63^{--} \\
(.25)\end{array}$ \\
\hline Unknown & $\begin{array}{c}.11 \\
(.15)\end{array}$ & $\begin{array}{l}.09 \\
(.10)\end{array}$ & $\begin{array}{l}.18 \\
(.18)\end{array}$ & $\begin{array}{l}-.06 \\
(.14)\end{array}$ & $\begin{array}{c}.11 \\
(.16)\end{array}$ & $\begin{array}{l}-.14 \\
(.12)\end{array}$ \\
\hline$x_{(11}^{b}$ & $4.21^{*}$ & 2.03 & $3.67^{\circ}$ & $5.42^{-\bullet}$ & $5.54^{\circ-}$ & 7.76 \\
\hline Drugs Ocher Than & & & & & & \\
\hline Cocaine & & & & & & \\
\hline Known & $\begin{array}{l}.50^{-0} \\
(.13)\end{array}$ & $\begin{array}{c}.39^{*} \\
(.15)\end{array}$ & $\begin{array}{l}1.17^{--} \\
(.33)\end{array}$ & $\begin{array}{l}1.01^{-} \\
(.33)\end{array}$ & $\begin{array}{l}1.31- \\
(.19)\end{array}$ & $\begin{array}{l}1.17^{-m} \\
(.18)\end{array}$ \\
\hline Unknown & $\begin{array}{l}.09 \\
(.10)\end{array}$ & $\begin{array}{c}.01 \\
(.07)\end{array}$ & $\begin{array}{l}-.05 \\
(.13)\end{array}$ & $\begin{array}{l}-.17 \\
(.11)\end{array}$ & $\begin{array}{l}.02 \\
(.12)\end{array}$ & $\begin{array}{l}-.07 \\
(.07)\end{array}$ \\
\hline$x_{(1)^{b}}$ & $6.41^{-}$ & $5.32 *$ & $11.91^{-\cdots}$ & $11.59^{\circ \cdots}$ & $35.93^{\cdots-}$ & $44.76^{\cdots}$ \\
\hline
\end{tabular}

Cocaine Plus Other

Drugs

\begin{tabular}{lllllll} 
Known & $1.00^{\cdots}$ & $.60^{\cdots}$ & $1.49^{\cdots}$ & $.99^{\cdots}$ & $1.56^{\cdots}$ & $1.04^{\circ}$ \\
Unknown & $(.16)$ & $(.09)$ & $(.22)$ & $(.15)$ & $(.21)$ & $(.14)$ \\
& $.69^{\cdots \cdots}$ & $.40^{\cdots}$ & $1.24^{\cdots}$ & $.94^{\circ}$ & $1.28^{\cdots}$ & $.91^{\circ}$ \\
& $(.17)$ & $(.13)$ & $(.24)$ & $(.16)$ & $(.22)$ & $(.12)$ \\
$X_{(1)^{6}}{ }^{6}$ & & & & & & \\
\hline
\end{tabular}

- Standard errors (in parentheses) have been corrected for heteroskedasticity with White's (1980) estimator. Omitted category is infant unexposed to any illicit drugs.

"A. Wald test of the null hypothesis that coefficients on known and unknown drug use are equal.

- $\mathrm{p}<.10$

$-p<.05$

$\cdots p<.01$ 
Table 6

Predicted length of stay and newborn costs for infants exposed and unexposed to exclusively cocaine (EC), drugs other than cocaine (DOC), and cocaine plus other drugs (CPOD) as recorded on discharge abstracts and based on specifications which exclude measures of newbom health.+

Exposed Unexposed Difference

EXCLUSIVELY

COCAINE

Length of stay

10.4

5.8

4.6

Newborn costs

$\$ 8,194$

$\$ 3,364$

$\$ 4,830$

DRUGS OTHER THAN

COCAINE

Length of stay

8.8

5.8

3.0

Newborn costs

$\$ 9,529$

$\$ 3,364$

$\$ 6,165$

COCAINE PLUS

OTHER DRUGS

Length of stay

14.1

5.8

8.3

Newbom costs

$\$ 12,591$

$\$ 3,364$

$\$ 9,227$

${ }^{+}$See footnotes to Table 3 
Table 7

Predicted length of stay and newborn costs for infanis exposed and unexposed to exclusively cocaine (EC), drugs other than cocaine (DOC), and cocaine plus other drugs (CPOD) as recorded on discharge abstracts and based on specifications which include measures of newborn bealth. ${ }^{+}$
Exposed
Unexposed
Difference

\section{EXCLUSIVELY}

COCAINE

Length of stay

5.1

3.9

1.2

Newborn costs

$\$ 3,331$

$\$ 2,209$

$\$ 1,122$

DRUGS OTHER THAN

COCAINE

Length of stay

5.6

3.9

2.7

Newborn costs

$\$ 5,624$

$\$ 2,209$

$\$ 3,415$

COCAINE PLUS

OTHER DRUGS

Length of stay

6.8

3.9

2.9

Newbom costs

$\$ 5,369$

$\$ 2,209$

$\$ 3,160$

${ }^{+}$See footnotes to Table 4 